\title{
AVALIAÇÃO DO AMBIENTE SOLO-SEMENTE POR MEIO DA TOMOGRAFIA COMPUTADORIZADA ${ }^{(1)}$
}

\author{
Alcir José Modolo(2), Haroldo Carlos Fernandes ${ }^{(3)}$, João de \\ Mendonça Naime $^{(4)}$, Carlos Ernesto G.R. Schaefer ${ }^{(5)}$, Nerilson Terra \\ Santos $^{(6)}$ \& João Cleber Modernel da Silveira ${ }^{(7)}$
}

\begin{abstract}
RESUMO
O condicionamento físico do solo ao redor das sementes reveste-se de grande importância para o bom desenvolvimento inicial da cultura, assegurando uma população sadia de plantas. $\mathrm{O}$ adequado contato solo-semente é um pré-requisito para a rápida emergência e o bom estabelecimento da cultura. Neste trabalho, objetivou-se utilizar a tomografia computadorizada de resolução milimétrica para determinação do ambiente solo-semente em sistema de plantio direto, logo após o plantio da cultura da soja. Utilizou-se o esquema de parcelas subdivididas, em que as parcelas constituíram-se de três teores de água do solo, correspondentes a 0,27 ; 0,$31 ;$ e $0,36 \mathrm{~kg} \mathrm{~kg}^{-1}$, e as subparcelas de quatro níveis de carga, aplicadas pela roda compactadora, correspondentes a 0,50,90 e $140 \mathrm{~N}$, no delineamento em blocos ao acaso, com quatro repetições. Foram avaliados a densidade média do solo na região da semente e o perfil de densidade média na linha de semeadura. De acordo com os resultados obtidos, pode-se concluir que as cargas aplicadas pela roda compactadora elevaram a densidade do solo no plano vertical da linha de semeadura abaixo da profundidade de semeadura, quando comparadas com as obtidas antes do plantio; a combinação entre cargas aplicadas pela roda compactadora e os teores de água no solo não influenciou a densidade média do solo na região da semente.
\end{abstract}

Termos de indexação: mecanização agrícola, compactação do solo, soja.

\footnotetext{
(1) Parte da Tese de Doutorado do primeiro autor. Área de concentração - Mecanização Agrícola, Universidade Federal de Viçosa - UFV. Recebido para publicação em outubro de 2006 e aprovado em novembro de 2007.

${ }^{(2)}$ Professor Adjunto do Curso de Agronomia, Universidade Tecnológica Federal do Paraná - UTFPR. Campus Pato Branco, Via do Conhecimento km 1, Caixa Postal 571, CEP 85501-970 Pato Branco (PR). E-mail: alcir@ufpr.edu.br

(3) Professor adjunto do Departamento de Engenharia Agrícola, Universidade Federal de Viçosa - UFV. Av. PH Rolfs s/n, CEP 36570-000 Viçosa (MG). E-mail: haroldo@ufv.br

(4) Pesquisador da Embrapa Instrumentação Agropecuária. Rua XV de novembro 1452, CEP 13560-970 São Carlos (SP). E-mail: naime@cnpdia.embrapa.br

(5) Professor adjunto do Departamento de Solos, UFV. E-mail: carlos.schaefer@ufv.br

(6) Professor adjunto do Departamento de Informática, UFV. E-mail: nsantos@ufv.br

(7) Doutorando em Mecanização Agrícola, UFV. Bolsista do CNPq. E-mail: jcmodernel@uol.com.br
} 


\title{
SUMMARY: EVALUATION OF THE SOIL-SEED ENVIRONMENT THROUGH COMPUTERIZED TOMOGRAPHY
}

\begin{abstract}
The physical conditioning of the soil around seeds is of great importance for an adequate initial development of a crop, ensuring a healthy plant population. A suitable soil-seed contact is a prerequisite for a fast crop germination and good establishment. In this study, computerized tomography of millimeter resolution was used to determine the soil-seed environment in a no tillage system, immediately after soybean planting. A split plot design was used, in which the plots consisted of three contents of soil water, corresponding to $0.27 ; 0,31$ and $0.36 \mathrm{~kg} \mathrm{~kg}^{-1}$, respectively, and the split plots of four load levels applied by the compaction wheel, corresponding to 0,50,90 and $140 \mathrm{~N}$, respectively. It was used a random block design, with four replications. The medium soil density in the seed area and the medium density profile in the sowing furrow were evaluated. According to the results, it may be concluded that: the loads applied by the compaction wheel increased soil density at the vertical planting level beneath planting depth as compared with values obtained before planting, and; the combination of wheel loads and soil water contents did not influence the mean soil density in the seed area.
\end{abstract}

Index terms: agricultural mechanization, soil compaction, soybean.

\section{INTRODUÇÃO}

O sucesso do estabelecimento de uma cultura depende do ambiente do solo que, inicialmente, deve ser adequado à germinação da semente, à emergência da plântula e, finalmente, ao desenvolvimento da planta. Para a cultura da soja, assim como para as demais culturas anuais, a semeadura e a adubação revestem-se de grande importância, pois eventuais problemas somente serão detectados após a germinação das plantas e seu desenvolvimento, quando a correção, difícil e onerosa, compromete a produtividade.

$\mathrm{O}$ adequado contato solo-semente é um pré-requisito para a rápida emergência e um bom estabelecimento da cultura (Perdok \& Kouwnhoven, 1994; Brown et al., 1996) e do ambiente em que a água estará disponível à semente.

A semeadura deve ser realizada no estádio de friabilidade do solo, pelo fato de os teores de água permitirem bom rendimento da operação e boa qualidade do trabalho realizado (Gassen \& Gassen, 1996). A semeadura realizada quando o solo se encontra acima do limite de plasticidade causa compactação e conseqüente redução da sua capacidade de infiltração; em solo seco, resulta em menor eficiência dos dispositivos sulcadores, que, por sua vez, ocasionam menor contato solo-semente (Kondo \& Dias Júnior, 1999).

Brown et al. (1996) e Silva (1990, 2002) relataram que, no processo de semeadura de culturas anuais, 0 condicionamento físico do solo ao redor das sementes reveste-se de importância capital para o bom desenvolvimento inicial da cultura, assegurando uma população adequada de plantas. Phillips \& Kirkhan
(1962) afirmaram que um condicionamento inadequado nesta fase pode limitar o desenvolvimento das plantas em estádios posteriores.

Vários autores têm procurado estudar a relação máquina-solo-planta em ensaios de semeadura utilizando rodas compactadoras. Furlani et al. (2001), combinando três profundidades de semeadura da cultura do milho com quatro níveis de compactação do solo sobre as sementes, não encontraram influência desses fatores sobre o número médio de dias para emergência das plântulas.

Em trabalho conduzido com diferentes tipos de rodas compactadoras na semeadura da soja, Hummel et al. (1981) afirmaram que o desempenho da roda compactadora teve considerável influência sobre o meio ambiente do solo em torno da semente. Relataram, ainda, que a compactação aplicada sobre o solo através de rodas compactadoras pode ou não ser benéfica às sementes, o que dependerá do nível de compactação e do desenho da roda, do tipo e teor de água do solo e das condições climáticas entre o período de semeadura e emergência.

Silva et al. (1991) verificaram a influência de quatro diferentes modelos de rodas compactadoras sobre o condicionamento físico do solo, utilizando três níveis de compactação condizentes com o processo de semeadura, e afirmaram que as rodas compactadoras alteram o comportamento hídrico do solo na região de semeadura, além de elevar a densidade e a resistência à penetração no plano vertical da linha de semeadura. A velocidade de emergência e a emergência total das plantas de feijoeiro foram afetadas pelas pressões de compactação. À medida que a compactação aumentou, as plântulas tiveram sua emergência retardada e diminuída para todas as rodas testadas. 
$\mathrm{O}$ estudo do ambiente solo-semente requer metodologias apropriadas, que possam melhor caracterizar a camada de solo próximo à semente. Os métodos tradicionais para a determinação da relação solo-semente e densidade próxima à semente são empíricos e não possuem sensibilidade suficiente, como o método da tomografia computadorizada.

Esse método fornece imagens contínuas de seções transversais de objetos, por meio do princípio da atenuação da radiação nos meios materiais (Macedo, 1997). Vários autores, desenvolvendo trabalhos com a tomografia computadorizada aplicada à física do solo, demonstraram sua utilização na determinação da densidade do solo em camadas muito finas e de forma contínua (Vaz et al., 1989; Crestana et al., 1992; Santos, 2000).

De acordo com Pedrotti et al. (2003), utilizando a técnica de tomografia computadorizada em amostras indeformadas de solo, é possível quantificar a densidade em perfis ortogonais à superfície do solo, permitindo a caracterização da densidade desde a superfície até a profundidade analisada e possibilitando que esses dados sejam apresentados em gráficos.

Vaz et al. (1989), utilizando um tomógrafo computadorizado de resolução milimétrica no estudo da compactação de solos causada por máquinas agrícolas, detectaram pequenas variações na densidade de camadas da ordem de milímetros.

Pedrotti (1996) comparou a tomografia computadorizada ao método do anel volumétrico para determinação da densidade do solo, visando avaliar a compactação de um solo cultivado em diferentes sistemas de manejo. Esse método apresentou vantagens, por permitir o detalhamento da variação da densidade ao longo do perfil, enquanto o anel volumétrico expressou um valor médio pouco representativo.

Neste trabalho, objetivou-se utilizar a tomografia computadorizada de resolução milimétrica para a determinação do ambiente solo-semente em sistema de plantio direto, logo após o plantio da cultura da soja.

\section{MATERIAL E MÉTODOS}

O experimento foi desenvolvido na Cooperativa Central Agropecuária de Desenvolvimento Tecnológico e Econômico Ltda. - COODETEC, localizada lateralmente à $\mathrm{BR} 467, \mathrm{~km}$ 98, sentido Cascavel Toledo, no Estado do Paraná, em um solo classificado, pela Embrapa (1999), como Latossolo Vermelho distroférrico típico, com relevo plano e textura argilosa. Utilizou-se o esquema fatorial $3 \times 4$, em que as parcelas constituíram-se de três teores de água (U1, U2 e U3), correspondentes a 0,27; 0,31; e 0,36 kg kg-1, respectivamente distribuídas em blocos ao acaso, qua quatro repetições, e as subparcelas de quatro níveis de carga aplicada pela roda compactadora $(\mathrm{C} 1, \mathrm{C} 2, \mathrm{C} 3$ e C4), correspondentes a 0,50, 90 e $140 \mathrm{~N}$, respectivamente.

A área foi subdividida em quatro blocos com quarenta e oito subparcelas experimentais, cada uma com área de $105 \mathrm{~m}^{2}$ (3,5 x $\left.30 \mathrm{~m}\right)$, com espaçamento de $1,0 \mathrm{~m}$ entre parcelas e de $15 \mathrm{~m}$ entre blocos, utilizados para manobra de um conjunto motomecanizado.

A caracterização física do solo antes do plantio foi feita determinando-se a densidade do solo, na camada de 0 a $15 \mathrm{~cm}$ de profundidade, sendo retiradas duas amostras em cada unidade experimental, utilizandose o método do anel volumétrico; a densidade de partículas, pela divisão da massa de sólidos correspondente a $20 \mathrm{~g}$ de TFSE (Terra Fina Seca em Estufa) pelo respectivo volume; a porosidade total, com base nas densidades das partículas e do solo, conforme descrito em Embrapa (1997).

Utilizou-se o cultivar de soja superprecoce CD 216, produzido pela COODETEC, com $87 \%$ de germinação mínima e $98 \%$ de pureza. Utilizou-se adubo de formulação 0-20-20 (N- $\left.\mathrm{P}_{2} \mathrm{O}_{5}-\mathrm{K}_{2} \mathrm{O}\right)$, sendo aplicados $300 \mathrm{~kg} \mathrm{ha}{ }^{-1}$ por ocasião da semeadura.

Para o plantio da soja no sistema plantio direto, utilizou-se um trator marca Ford, modelo 76304 x 2 com tração dianteira auxiliar (TDA), potência de $75,8 \mathrm{~kW}(103 \mathrm{cv})$ e uma semeadora-adubadora de precisão marca Vence Tudo, modelo SMT 6414 de arrasto, com mecanismos sulcadores do tipo haste sulcadora para fertilizantes e discos duplos defasados para sementes e, com mecanismos de cobertura e compactação do tipo roda compactadora de borracha, tipo convexa com $330 \mathrm{~mm}$ (13”) de diâmetro e $170 \mathrm{~mm}$ de largura. Antes da realização do ensaio, a semeadora foi regulada visando à distribuição de 25 sementes por metro (equivalente a 556.000 sementes ha-1) e profundidade de plantio de $5 \mathrm{~cm}$.

Para determinar o nível de carga aplicada pela roda compactadora sobre a semente, utilizou-se uma célula de carga da marca Kratos, modelo 2BL1601, com capacidade de $19,6 \mathrm{kN}$, acoplada sobre a roda compactadora. O pino que fixa a roda compactadora foi retirado de modo que essa ficasse livre e toda a carga fosse aplicada diretamente na célula de carga. As cargas aplicadas pela roda compactadora sobre a semente foram visualizadas em um visor da marca Kratos, modelo IK-14A, da Kratos Equipamentos Industriais Ltda. A figura 1 mostra os equipamentos utilizados no ensaio.

A densidade média do solo na região da semente e o perfil de densidade foram obtidos mediante o uso do método da tomografia computadorizada. Após a realização da semeadura, foram coletadas quatro amostras indeformadas de solo em cada unidade experimental, dentro das quais estaria contida a semente (Reis et al., 2002). Essas amostras foram coletadas sobre a linha central de plantio, onde foram cravados, no solo, quatro cilindros de $16 \mathrm{~cm}$ de altura por $4 \mathrm{~cm}$ de diâmetro. 
As análises foram realizadas com o uso de um tomógrafo de terceira geração (Naime, 2001), constituído de um sistema fonte-detector posicionado em uma guia circular, que realiza movimentos de rotação ao redor da amostra. Utilizaram-se uma fonte de raios gama $\left({ }^{241} \mathrm{Am}, \mathrm{E}=59,54 \mathrm{keV}, 1,11 \mathrm{GBq}\right)$ e um arranjo de 256 detectores, compostos de material semicondutor (Figura 2). Os movimentos de elevação e rotação foram executados por dois motores de passo, controlados por um sistema eletrônico e um computador dedicado à eletrônica embarcada-padrão $\mathrm{PC} / 104$.

Para que a semente não desse início ao processo de embebição, as amostras contidas nos cilindros foram secas em estufa a $50{ }^{\circ} \mathrm{C}$, por $48 \mathrm{~h}$. Posteriormente,
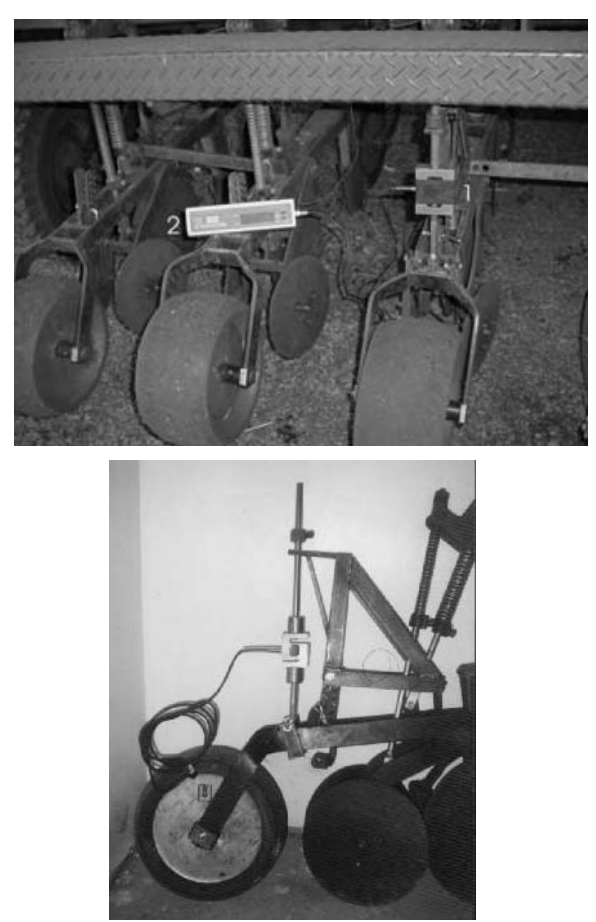

Figura 1. Vista geral dos equipamentos utilizados na determinação das cargas aplicadas no solo pela roda compactadora: (1) célula de carga, (2) visor.

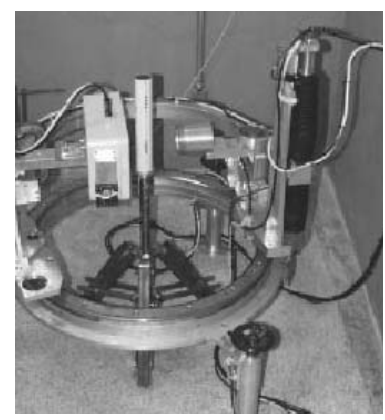

Figura 2. Vista geral do tomógrafo utilizado para determinação da densidade média do solo. Fonte: Naime (2001). elas foram colocadas na base do tomógrafo, dando início à obtenção das imagens. Trabalhou-se com 33 planos horizontais, em que o feixe em leque atravessou a amostra de $5 \mathrm{em} 5 \mathrm{~cm}$, até a profundidade de $16 \mathrm{~cm}$.

A expressão geral que descreve a interação de um feixe de fótons e a amostra de solo com a semente é:

$$
\mathrm{I}=\mathrm{I}_{0} \mathrm{e}^{-\int \mu \mathrm{dx}}
$$

em que I = intensidade da radiação do feixe emergente, contagem por segundo; $\mathrm{I}_{0}=$ intensidade da radiação do feixe incidente, contagem por segundo; $\mu=$ coeficiente de atenuação linear do solo, $\mathrm{cm}^{-1}$; e x $=$ espessura da amostra, cm.

$\mathrm{O} \mu$ foi calculado relacionando-se o coeficiente de atenuação em massa $\left(\mu_{\mathrm{m}}\right)$ com a densidade do material ( $\rho)$, isto é:

$$
\mu=\mu_{\mathrm{m}} \rho
$$

A densidade foi determinada por meio da seguinte equação:

$$
\rho=\frac{1}{\mathrm{x}_{\mathrm{m}}} \ln \frac{\mathrm{I}_{0}}{\mathrm{I}}
$$

em que $\mathrm{I}_{0}=$ radiação que atravessa o recipiente vazio, contagem por segundo; $\mathrm{I}$ = radiação que atravessa a unidade experimental, no sentido horizontal, contagem por segundo; $\mathrm{x}=$ espessura interna do recipiente, $\mathrm{cm}$; e $\mu_{\mathrm{m}}=$ coeficiente de atenuação em massa do solo, $\mathrm{cm}^{2} \mathrm{~g}^{-1}$.

O coeficiente médio de atenuação em massa, obtido experimentalmente para o solo em estudo, foi de $0,4140 \mathrm{~cm}^{2} \mathrm{~g}^{-1}$. A partir desse valor, foram obtidos os valores de densidade do solo na região da semente.

Um programa de reconstrução e visualização de imagens, desenvolvido com base na linguagem Visual Basic da Microsoft e Borland C++ Builder (Naime, 2001), foi responsável pelo processamento dos dados, ou pela retroprojeção e apresentação da imagem.

Os resultados obtidos para a caracterização física do solo foram submetidos à análise de variância, e as médias foram comparadas pelo teste de Tukey, a $5 \%$. Os resultados referentes à densidade do solo na região da semente foram submetidos à análise em superfície de resposta por meio do procedimento GLM do "Statistical Analysis System" (SAS, 1989). Os modelos foram escolhidos com base no teste para a falta de ajustamento do modelo de superfície, na significância do teste $t$ dos coeficientes de regressão a $5 \%$.

\section{RESULTADOS E DISCUSSÃO}

A figura 3 mostra as imagens tomográficas ilustrativas, utilizadas para a determinação da densidade média do solo na região da semente, para 
os diferentes teores de água do solo e cargas aplicadas pela roda compactadora. As imagens tomográficas representam a densidade do solo em uma escala de 16 tons de cinza, em que as sementes são caracterizadas pelas áreas com formato arredondado, de coloração mais escura (menores valores de densidade), enquanto as áreas de coloração mais clara indicam maiores valores de densidade.

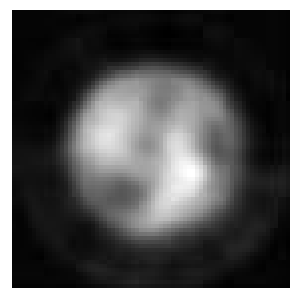

$\mathrm{U} 1 \mathrm{C} 1$

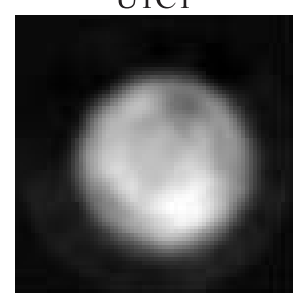

$\mathrm{U} 2 \mathrm{C} 1$

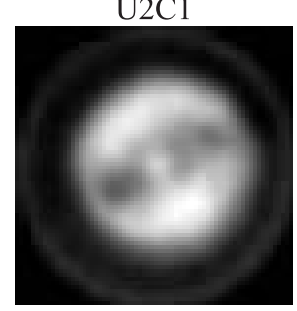

U3C1

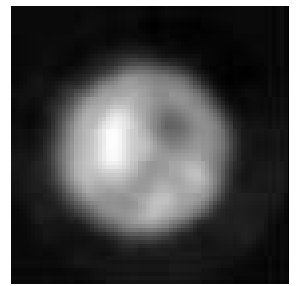

$\mathrm{U} 1 \mathrm{C} 2$

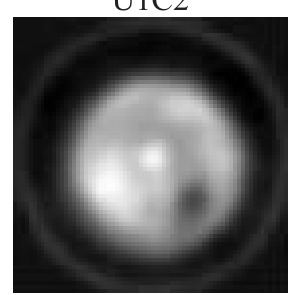

$\mathrm{U} 2 \mathrm{C} 2$

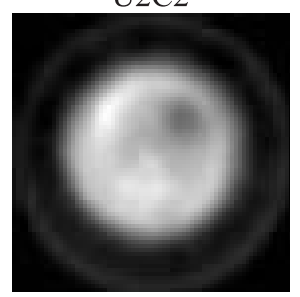

$\mathrm{U} 3 \mathrm{C} 2$

\section{Caracterização física do solo}

Os resultados obtidos com a análise de variância permitem concluir que as unidades experimentais que foram alocadas para receber os 12 tratamentos estavam sob condições bastante homogêneas com relação à densidade do solo, à densidade de partículas e à porosidade total do solo (Quadro 1).

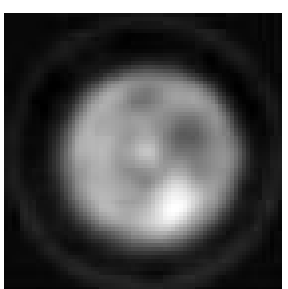

$\mathrm{U} 1 \mathrm{C} 3$

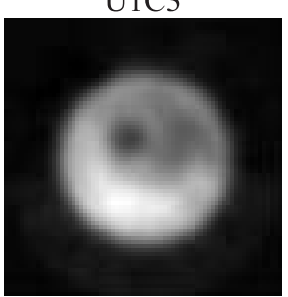

$\mathrm{U} 2 \mathrm{C} 3$

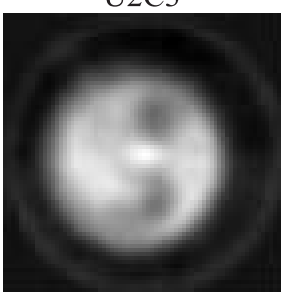

$\mathrm{U} 3 \mathrm{C} 3$

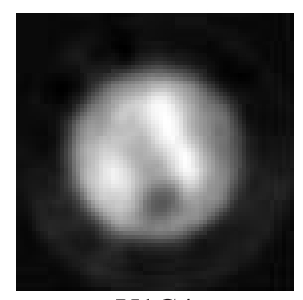

$\mathrm{U} 1 \mathrm{C} 4$

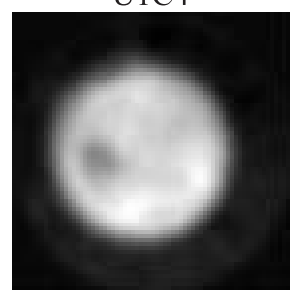

$\mathrm{U} 2 \mathrm{C} 4$

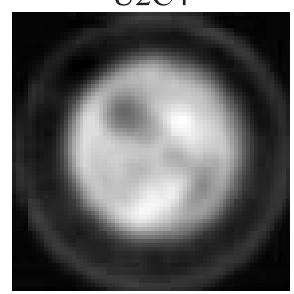

$\mathrm{U} 3 \mathrm{C} 4$

Figura 3. Imagens tomográficas da densidade média do solo na região da semente para os diferentes teores de água do solo e níveis de carga aplicada pela roda compactadora.

Quadro 1. Densidade do solo, densidade de partículas e porosidade total para todos os tratamentos na camada de 0 a $15 \mathrm{~cm}$

\begin{tabular}{lccc}
\hline \multirow{2}{*}{ Tratamento } & Densidade do solo & Densidade de partículas & Porosidade total \\
\hline & & & $\mathrm{m}^{3} \mathrm{~m}^{-3}$ \\
U1C1 & 1,19 & 2,87 & 0,59 \\
U1C2 & 1,21 & 2,83 & 0,57 \\
U1C3 & 1,21 & 2,88 & 0,59 \\
U1C4 & 1,22 & 2,78 & 0,56 \\
U2C1 & 1,23 & 2,83 & 0,56 \\
U2C2 & 1,20 & 2,87 & 0,58 \\
U2C3 & 1,22 & 2,88 & 0,58 \\
U2C4 & 1,21 & 2,85 & 0,58 \\
U3C1 & 1,21 & 2,79 & 0,57 \\
U3C2 & 1,23 & 2,88 & 0,57 \\
U3C3 & 1,20 & 2,84 & 0,58 \\
U3C4 & 1,19 & 2,83 & 0,58 \\
CV (\%) & 2,06 & 2,02 & 2,34 \\
DMS & 0,06 & 0,14 & 0,03 \\
\hline
\end{tabular}




\section{Densidade média do solo na linha de semeadura}

A análise de variância do teste $\mathrm{F}$, para falta de ajustamento do modelo de regressão, para a densidade média do solo na região da semente é apresentada no quadro 2.

$\mathrm{O}$ teste $\mathrm{F}$ para a falta de ajustamento indica que o modelo de regressão adotado se ajusta bem aos dados, podendo ser utilizado para avaliar a significância dos fatores teores de água do solo (U) e das cargas aplicadas pela roda compactadora $(\mathrm{C})$ sobre a variável densidade média do solo na região da semente. No entanto, o teste $\mathrm{F}$ para a regressão do modelo ajustado possibilita concluir que os teores de água do solo (U) e as cargas aplicadas pela roda compactadora (C) não tiveram efeito significativo sobre a variável densidade média do solo na região da semente. Embora não-significativo, o teor de água $0,31 \mathrm{~kg} \mathrm{~kg}^{-1}$ e a carga aplicada pela roda compactadora de $50 \mathrm{~N}$ apresentaram o maior valor de densidade média na região da semente.

Os valores médios obtidos para a variável densidade média do solo na região da semente medida por tomografia, nos diferentes tratamentos, estão no quadro 3.

Nas figuras 4, 5 e 6 estão os perfis dos valores médios da densidade média do solo obtida por tomografia computadorizada nos teores de água 0,27 , 0,31 e $0,36 \mathrm{~kg} \mathrm{~kg}^{-1}$, respectivamente.

Quadro 2. Análise de variância do teste F, para falta de ajustamento do modelo de regressão, para a densidade média do solo na região da semente

\begin{tabular}{lrcccc} 
Fonte de variação & GL & SQ & QM & F & Pr $>$ F \\
\hline Regressão & 5 & 0,080 & 0,016 & $1,12^{\text {ns }}$ & 0,37 \\
Falta Ajustamento & 6 & 0,095 & 0,016 & $1,12^{\text {ns }}$ & 0,37 \\
Tratamentos & 11 & 0,175 & - & - & - \\
Resíduo & 33 & 0,469 & 0,014 & & \\
\hline
\end{tabular}

ns: não-significativo a $5 \%$.
Nota-se que na profundidade de semeadura de $6,0 \mathrm{~cm}$, os tratamentos compostos pelo teor de água $0,27 \mathrm{~kg} \mathrm{~kg}^{-1}$ apresentaram valores semelhantes de densidade média, independente das cargas aplicadas pela roda compactadora (Figura 4). Quanto aos

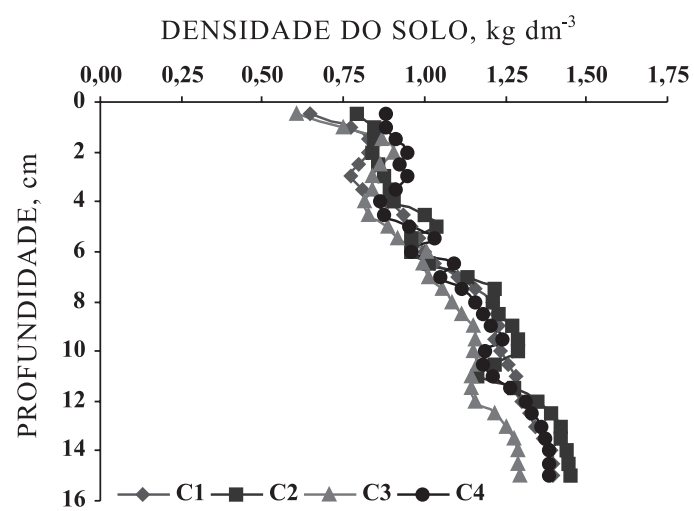

Figura 4. Perfil da densidade média do solo obtida por tomografia computadorizada para o teor de água do solo $\mathrm{U}=0,27 \mathrm{~kg} \mathrm{~kg}^{-1}$, em razão das cargas aplicadas $(\mathrm{C} 1=0 \mathrm{~N}, \mathrm{C} 2=50 \mathrm{~N}, \mathrm{C} 3=90 \mathrm{~N}$ e $\mathrm{C} 4=$ $140 \mathrm{~N})$.

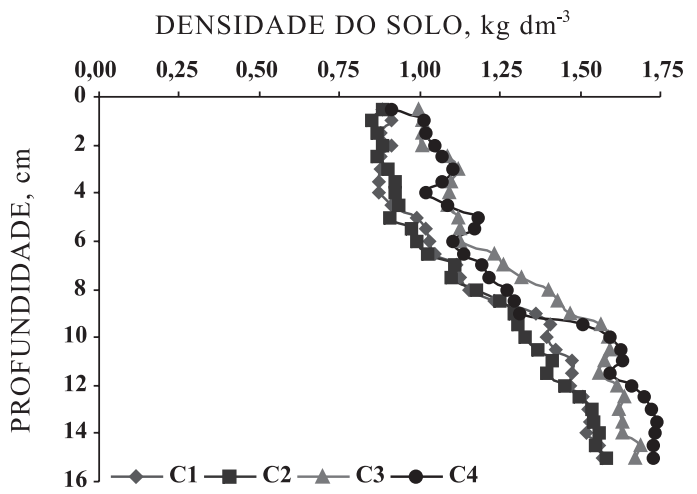

Figura 5. Perfil da densidade média do solo obtida por tomografia computadorizada para o teor de água do solo $\mathrm{U}=0,31 \mathrm{~kg} \mathrm{~kg}^{-1}$, em razão das cargas aplicadas $(\mathrm{C} 1=0 \mathrm{~N}, \mathrm{C} 2=50 \mathrm{~N}, \mathrm{C} 3=90 \mathrm{~N}$ e C4 $=$ $140 \mathrm{~N})$.

Quadro 3. Densidade média do solo na região da semente de acordo com o teor de água e a carga aplicada

\begin{tabular}{|c|c|c|c|c|c|}
\hline \multirow{2}{*}{ Teor de água } & \multicolumn{4}{|c|}{ Cargas aplicadas (N) } & \multirow{2}{*}{ Média } \\
\hline & 0 & 50 & 90 & 140 & \\
\hline \multicolumn{6}{|l|}{$\mathrm{kg} \mathrm{kg}^{-1}$} \\
\hline $\begin{array}{l}0,27 \\
0,31 \\
0,36\end{array}$ & $\begin{array}{l}1,04 \\
1,04 \\
1,00\end{array}$ & $\begin{array}{l}1,10 \\
1,12 \\
1,01\end{array}$ & $\begin{array}{l}0,92 \\
1,04 \\
0,96\end{array}$ & $\begin{array}{l}0,99 \\
1,11 \\
0,96\end{array}$ & $\begin{array}{l}1,01 \\
1,08 \\
1,00\end{array}$ \\
\hline Média & 1,03 & 1,08 & 0,97 & 1,02 & 1,03 \\
\hline
\end{tabular}


tratamentos compostos pelo teor de água $0,31 \mathrm{~kg} \mathrm{~kg}^{-1}$, nota-se que os tratamentos U2C3 e U2C4, compostos pelas maiores cargas aplicadas pela roda compactadora (90 e $140 \mathrm{~N})$, respectivamente, tenderam a apresentar os maiores valores de densidade média (Figura 5). Já como teor de água $0,36 \mathrm{~kg} \mathrm{~kg}^{-1}$, as maiores densidades foram observadas nos tratamentos compostos pelas cargas U3C1 e U3C3.

Verificou-se também que a densidade do solo aumenta da superfície para baixo, atingindo os maiores valores nas maiores profundidades. Os maiores valores de densidade média observados foram 1,45, 1,74 e 1,68 $\mathrm{kg} \mathrm{dm}^{-3}$, para os teores de água 0,27, 0,31 e $0,36 \mathrm{~kg} \mathrm{~kg}^{-1}$, respectivamente.

Não há consenso entre os autores sobre o nível crítico da densidade do solo (valor acima do qual o solo é considerado compactado). Camargo \& Alleoni (1997) consideram crítico o valor de $1,55 \mathrm{~kg} \mathrm{dm}^{-3} \mathrm{em}$ solos franco-argilosos a argilosos. De Maria et al. (1999) constataram que, na densidade do solo acima de 1,2 kg dm${ }^{3}$, no Latossolo Roxo, ocorre restrição ao desenvolvimento de raízes quando o solo estiver na capacidade de campo, o que caracteriza um estado de compactação do solo. Queiroz-Woltans et al. (2000), avaliando o efeito da compactação do solo na anatomia da raiz e no desenvolvimento de dois cultivares de soja, constataram que valores de densidade do solo abaixo de $1,5 \mathrm{~kg} \mathrm{dm}^{-3}$ não afetaram o desenvolvimento dos cultivares.

Nenhum dos valores encontrados nos tratamentos compostos pelo teor de água $0,27 \mathrm{~kg} \mathrm{~kg}^{-1}$ (Figura 4) superou o valor considerado crítico pela literatura (1,55 kg dm ${ }^{-3}$ ) (Camargo \& Alleoni, 1997). Com o teor de água $0,31 \mathrm{~kg} \mathrm{~kg}^{-1}$ (Figura 5), apenas os tratamentos U2C1 e U2C2 foram inferiores, podendose inferir que não ocorreu compactação superficial ou em profundidade no solo para esses tratamentos. Por outro lado, todos os tratamentos compostos pelo teor de água 0,36 kg kg-1 (Figura 6) apresentaram valores superiores a $1,55 \mathrm{~kg} \mathrm{dm}^{-3}$ em profundidades maiores

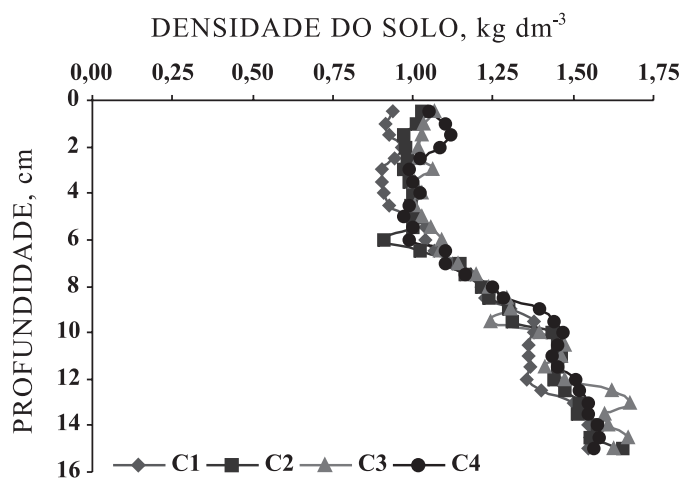

Figura 6. Perfil da densidade média do solo obtida por tomografia computadorizada para o teor de água do solo $\mathrm{U}=0,36 \mathrm{~kg} \mathrm{~kg}^{-1}$, em razão das cargas aplicadas $(\mathrm{C} 1=0 \mathrm{~N}, \mathrm{C} 2=50 \mathrm{~N}, \mathrm{C} 3=90 \mathrm{~N}$ e C4 $140 \mathrm{~N})$. que $13 \mathrm{~cm}$. Valores esses que podem influenciar o desenvolvimento radicular da cultura, fazendo com que as raízes se concentrem na superfície do solo, acarretando um estande deficiente de plantas em períodos de déficit hídrico.

A maior densidade do solo observada abaixo de $10,0 \mathrm{~cm}$ de profundidade em todos os tratamentos estudados, em relação à densidade do solo antes da realização do ensaio (Quadro 1), deve ser decorrente da transmissão da carga aplicada na superfície do solo pela roda compactadora.

\section{CONCLUSÕES}

1. As cargas aplicadas pela roda compactadora elevaram a densidade do solo no plano vertical da linha de semeadura abaixo da profundidade de semeadura, quando comparadas com os valores obtidos antes do plantio.

2. A combinação entre cargas aplicadas pela roda compactadora e teores de água no solo não influenciou a densidade média do solo na região da semente.

\section{AGRADECIMENTOS}

Os autores agradecem ao CNPq pelo apoio financeiro para realização deste trabalho; à COODETEC pela área e estrutura física cedidas para a realização do experimento.

\section{LITERATURA CITADA}

BIASSUSI, M. Estudo da deformação de um vertissolo através da tomografia computadorizada de dupla energia. Pelotas, Universidade Federal de Pelotas, 1996. 80p. (Tese de Mestrado)

BROWN, A.D.; DEXTER, A.R.; CHAMEN, W.C.T. \& SPOOR, G. Effect of soil macroporosity and agregate size on seed-soil contact. Soil \& Till. Res., 38: 203-216, 1996.

CAMARGO, O.A. \& ALLEONI, L.R.F. Compactação do solo e o desenvolvimento das plantas. Piracicaba, Escola Superior de Agricultura Luiz de Queiroz, 1997. 132p.

CRESTANA, S.; CRUVINEL, P.E.; VAZ, C.M.P.; CESAREO, R.; MASCARENHAS, S. \& REICHARDT, K. Calibração e uso de um tomógrafo computadorizado em ciência do solo. R. Bras. Ci. Solo, 16:161-167, 1992.

DE MARIA, I.C.; CASTRO, O.M. \& DIAS, H.S. Atributos físicos do solo e crescimento radicular de soja em Latossolo Roxo sob diferentes métodos de preparo do solo. R. Bras. Ci. Solo, 23: 703-709, 1999. 
EMPRESA BRASILEIRA DE PESQUISA AGROPECUÁRIA EMBRAPA. Centro Nacional de Ciência do Solo. Manual de métodos de análise de solos. 2.ed. Rio de Janeiro, 1997. 212 p.

EMPRESA BRASILEIRA DE PESQUISA AGROPECUÁRIA EMBRAPA - EMBRAPA. Centro Nacional de Pesquisa de Solos. Sistema brasileiro de classificação de solos. Rio de Janeiro, 1999. 412p.

FURLANI, C.E.A.; LOPES, A.; REZENDE, L.C.; SOUZA \& SILVA, S.S. \& LEITE, M.A.S. Influência da compactação do solo na emergência das plântulas de milho a diferentes profundidades de semeadura. Eng. Agric., 9:147-53, 2001.

GASSEN, D. \& GASSEN, F. Plantio direto: o O caminho do futuro. Passo Fundo, Aldeia Sul, 1996. 27p.

HUMMEL, J.W.; GRAY, L.E. \& NAVE, W.R. Soybean emergence from field seedbed environments. Trans. Am. Soc. Agric. Eng., 24:872-878, 1981.

JOSCHKO, M.; MULLER, P.C.; KOTZKE, K.; DOHRING, W. \& LARINK, O. Earthworm burrow system development assessed by means of X-ray computed tomography. Geoderma, 56: 209-221, 1993.

KONDO, M.K. \& DIAS JÚNIOR, M.S. Efeito do manejo e da umidade no comportamento compressivo de três latossolos. R. Bras. Ci. Solo, 23:497-506, 1999.

MACEDO, I.A. Construção e uso de um tomógrafo com resolução micrométrica para aplicações em ciências do solo e do ambiente. 1997. São Paulo, Universidade de São Paulo, 1997. 129p. (Tese de Doutorado)

NAIME, J.M. Um novo método para estudos dinâmicos, in situ, da infiltração da água na região não-saturada do solo. São Paulo, Universidade de São Paulo, 2001. 146p. (Tese de Doutorado)

PEDROTTI, A. Avaliação da compactação de um planossolo submetido a diferentes sistemas de cultivo. Pelotas, Universidade Federal de Pelotas, 1996. 83p. (Tese de Mestrado)

PEDROTTI, A.; PAULETTO, E.A.; CRESTANA, S.; CRUVINEL, P.E.; VAZ, C.M.P.; NAIME, J.M. \& SILVA, A.M. Tomografia computadorizada aplicada a estudos de um Planossolo. Pesq. Agropec. Bras., 38:819-826, 2003.
PERDOK, U.D. \& KOUWENHOVEN, J.K. Soil-tool interactions and field performance of implements. Soil Till. Res., 30:283-326, 1994.

PHILLIPS, R.E. \& KIRKHAN, D. Mechanical impedance and corn seedling root growth. Soil Sci. Soc. Am. Proc., 26:319$22,1962$.

QUEIROZ-VOLTAN, R.B.; NOGUEIRA, S.S.S. \& MIRANDA, M.A.C. Aspectos da estrutura da raiz e do desenvolvimento de plantas de soja em solos compactados. Pesq. Agropec. Bras., 35:929-938, 2000.

REIS, E.F.; SCHAEFER, C.E.G.R.; VIEIRA, L.B.; SOUZA, C.M. \& FERNANDES, H.C. Avaliação do contato solo-semente em um solo argiloso sob plantio direto, com diferentes teores de água no solo. Eng. Agric., 10:31-39, 2002.

SANTOS, C.S.V. Formação de camadas superficiais adensadas em solo argiloso em resposta a flutuações de umidade. Viçosa, MG, Universidade Federal de Viçosa, 2000. 70p. (Tese de Doutorado)

SAS-WINDOWS Institute Corporation - Propriety software release 6.08. Cary, 1989.

SILVA, F.M. Influência do tipo de rodas compactadoras de semeadoras-adubadoras, no condicionamento físico do solo e no desenvolvimento de plantas. 1990. Campinas, Universidade Estadual de Campinas, 1990. 131p. (Tese de Mestrado)

SILVA, F.M.; ORTOLANI, F.M. \& DANIEL, L.A. Rodas compactadoras de semeadoras-adubadoras - influência no condicionamento físico do solo na região de semeadura. In: CONGRESSO BRASILEIRO DE ENGENHARIA AGRÍCOLA, 20., Londrina, 1991. Anais. Londrina, Sociedade Brasileira de Engenharia Agrícola, 1991. p.1126-1146.

SILVA, R.P. Efeito de rodas compactadoras submetidas a cargas verticais em profundidades de semeadura nas características agronômicas do milho (Zea Mays L.). Jaboticabal, Universidade Estadual Paulista, 2002. 101p. (Tese de Doutorado)

VAZ, C.M.P.; CRESTANA, S.; MASCARENHAS, S.; CRUVINEL, P.E.; RERICHARDT, K. \& STOLF, R. Using a computed tomography miniscanner for studying tillage induce soil compaction. Soil Technol., 2:313-321, 1989. 